\title{
Carbon Footprint Assessment in the Life-Cycle Design of Concrete Structures in the Tropics: A Case Study of Residential Buildings in Malaysia
}

\author{
Farnaz Jahandideh $^{1 \mathrm{a}}$, Sudharshan N. Raman ${ }^{1 \mathrm{~b}^{*}}$, Maslina Jamil ${ }^{1 \mathrm{c}}$, Zubair I. Syed ${ }^{2 \mathrm{~d}}$ \\ ${ }^{1}$ Department of Architecture and Built Environment, Faculty of Engineering and Built \\ Environment, \\ Universiti Kebangsaan Malaysia, 43600 UKM Bangi, Selangor, Malaysia \\ ${ }^{2}$ Department of Engineering, School of Computing, Engineering and Digital Technologies, \\ Teesside University, Middlesbrough, TS1 3BX, United Kingdom.
}

fzjahandideh@gmail.com ${ }^{a}$,snraman@gmail.com ${ }^{b *}$, pghinovasi@ukm.edu.myc, z.syed@tees.ac.uk

Published: $31^{\text {st }}$ August 2020

\begin{abstract}
With the exponential growth in development of cities and increasing demand for construction, which is one of the factors in environmental degradation, the need for $\mathrm{CO} 2$ emissions control is essential. In order to balance carbon emissions along the life-cycle of concrete structures; in this paper, we have analysed the carbon emissions and assessed the carbon footprint of selected concrete structures in a tropical city. For this purpose, the carbon footprint has been evaluated using Life-Cycle Sustainability Assessment (LCSA) approach at different stages concrete structures' life-cycle, which are production, construction, operation, and demolition stages, where the $\mathrm{CO} 2$ footprint of two residential buildings in Malaysia have been analysed as case studies. The findings indicated that the energy consumption, and the production phase in the life-cycle of a concrete structure are the main contributors of $\mathrm{CO} 2$ emission. In addition, detailed analysis of the carbon cycle in structures and their interaction with other components involved in the regional eco-system can lead to a significant reduction in $\mathrm{CO} 2$ emission, and thus to the improvement in reducing environmental deterioration and its consequences. Moreover, optimised design and customisation to the constituents of concrete, as well as improving citizens' consumption agenda can significantly reduce the carbon emission of concrete structures.
\end{abstract}

Keywords: Carbon emission, $\mathrm{CO}^{2}$ emission, Concrete structures, Life-cycle design, Life-Cycle Sustainability Assessment (LCSA).

\section{INTRODUCTION}

The emission of greenhouse gases is one of the major problems facing civilisation in the modern world. To address this issue, it is essential to incorporate all the industrial sectors, which are responsible for the global $\mathrm{CO} 2$ emissions in the analysis process of carbon footprint contribution. This is certainly relevant to the cement manufacturing industry, which produces approximately $7 \%$ of the carbon dioxide emitted into the surrounding environment (Pradipto \& Afif, 2019; Fantili et al., 2019).

Concrete structures contribute significant environmental impacts, which is rooted in its investment in terms of raw materials and energy (Sharif et al., 2017). In recent years, the need for sustainability in concrete structures and reducing its impact on the environment has been the attention centre and these issues are envisaged to intensify in the coming years. There are incontrovertible issues related to concrete construction, which results in it being viewed as a menace to the environment (Caruso et al., 2017). Energy consumption and carbon emission are the two most important environmental issues related to concrete structures (Latawiec et al., 2018).

As low carbon footprint and sustainable design solutions have root in design and material choices, there is an incumbency to study the contribution of concrete to the embodied energy and carbon footprint of a building during its production and construction phases of its lifecycle (Sulaiman et al., 2018). Substantial amount of research has been undertaken on the utilisation of concrete and its different ingredients, and cement replacements materials in concrete production (Rohden \& Garcez, 2018). While many of these studies have 
focussed on the environmental impact of residential concrete buildings, the studies focussing on concrete structures in tropical cities have been limited. Hence, it is necessary to assess carbon footprint, as well as the sustainability aspect over the life-cycle of concrete buildings comprehensively, through a detailed framework (Kajaste \& Hurme, 2016).

In undertaking this study, the Life-Cycle Sustainability Assessment (LCSA) framework for assessing concrete residential building's footprint over their life span have been adopted, and $\mathrm{CO} 2$ emission resources in concrete structures have been analysed, and subsequently to develop an improved sustainability framework for concrete structures. Notwithstanding differing views on the exact life-cycle of a concrete structures, a 50 years' life-cycle for residential buildings have been considered in this study. Based on this definition, the life-cycle length of time can be construed as starting from the material production cycle until their end of life (Besten et al., 2018).

Basically, there are four main phases in a building's life-cycle; i.e. materials production, building construction, building operation and maintenance, and end of life phase (Chau et al., 2015). In order to determine the $\mathrm{CO} 2$ emission and environmental impact of a building, there is a need to study these components throughout all its life-cycle phases.

\section{METHODOLOGY}

In this study, the methodology for LCSA of concrete structures have been considered based on the principles defined in ISO 14040 (2006), ISO 14044 (2006) and corresponding sets of international standards. This framework examines the socio-economic and environmental impacts of a product to assess its sustainability and environmental impacts through its lifecycle. Basically, the LCSA framework is used to estimate the environmental impacts through a product's life-cycle and the changes on the ecosystems (Venkatarama Reddy, 2009). A number of researchers in the field of sustainability have adopted the LCSA methodology function in the $\mathrm{CO} 2$ emission assessment of a product life-cycle and its environmental impacts (Woon et al., 2019; Dakwale et al., 2011). The carbon emission of concrete building's life-cycle can be monitored using the Life-Cycle Carbon Emission Assessment (LCCEA) model, which has been developed in the LCSA method (Jahandideh et al., 2017).

\subsection{Method of Analysis of LCSA in the Construction Industry}

The approach of LCSA describes the key instrument used to measure adverse effects on different climate conditions and ecosystem modifications correlated with the life-cycle of the structure (Miller et al., 2018). LCSA study is typically described in the form of accumulation of environmental loads, impacts of economic aspects or impacts per unit of construction practices, and the social life-cycle assessment, without considering the possibility of their allocation in time and space (Sharma et al., 2012). Recently, related international practitioners and researchers have also acknowledged the successful role of the LCSA approach in the quantitative evaluation of $\mathrm{CO} 2$ pollution and its environmental and economic consequences (Kofoworola \& Gheewala, 2008).

\subsection{Life-Cycle of Concrete Residential Building: Definition}

In this paper, a 50-year life span for concrete residential buildings have been adopted, in keeping with the predominant design criteria in Malaysia, irrespective of what a residential building's exact life-cycle is. Through a building life-cycle approach, the research phase ranges from the production of the raw materials used by structures to their final destruction where all sorts of waste are processed or reused (Ramesh et al., 2012). There are usually four sequential stages, such as the production phase, construction and reformation phase, service life phase, and building End-of-Life (EOL) (Giesekam et al., 2015). All of those stages must be applied to evaluate the $\mathrm{CO} 2$ and environmental pollution and the environmental effect of residential buildings on their life-cycle.

\subsection{Main Source of $\mathrm{CO} 2$ Emission in Concrete Structures}

According to the Intergovernmental Panel on Climate Change (IPCC) report (2018), emission of $\mathrm{CO} 2$ in residential buildings arise from three main sources; industrial and chemical activity, transportation, and energy consumption. Thus, it can be deduced that the occupation of land and making changes in preparation of construction, as well as the process of material production and transportation to the project site, and ultimately the energy consumption during the construction and operation phase are all contributing factors to $\mathrm{CO} 2$ emission of concrete structures (Hafizzudin et al., 2019). 
Due to lack of data in the present case study, the land footprint $\mathrm{CO} 2$ emission were not considered in the analysis. Based on the information provided, the total life-cycle $\mathrm{CO} 2$ emissions of residential structures can be calculated through the Equations (1) to (3), as follows:

$$
T E=\sum_{p=1}^{4}\left(I C_{p}+E C_{P}+T\right)
$$

where, $T E$ is the total emission during the building's life-cycle, $p$ is the different phases of a building life-cycle, from Phase 1 to Phase 4, IC and $E C$ are industrial and chemical, and energy consumption respectively. $T$ also is a symbol of transportation.

$$
I C_{p}=\sum_{m=1}^{2}\left(M_{p m} \times C F_{m}\right)
$$

Eq. (2) above represents the calculation of the exact amount of industrial and chemical activities $(I C)$. Here, $m$ is the types of materials used in the structure that contribute to $\mathrm{CO} 2$ emission, where in this study, we have only considered cement and steel reinforcement. $M$ is the intended material and $C F$ is the conversion factor, where it is $0.396 t / t$ for cement and $0.319 t / t$ for steel (You et al., 2011).

$$
E C_{p}=\sum_{k=1}^{n}\left(M_{p k} \times C F_{k}\right)
$$

Energy consumption is computed using Eq. (3) above, where $k$ is type of energy used in different phases of the building's life-cycle. $M$ introduces the intended energy, which in this case is electricity, and as mentioned, $C F$ is the conversation factor for $k$.

\subsection{Building Materials Production Phase}

As mentioned previously, the industrial and chemical process of the production phase, as well as the energy consumption in the production phase are the main sources of the $\mathrm{CO} 2$ emission in the production phase, i.e. since the inputs of materials and energy take place intensively in this phase (Fiala et al., 2013). The industrial and chemical process related to cement production emission, which is rooting in the limestone disintegration, and the energy consumption is referred to as emission from electricity and initial energy consumption during the life-cycle of the building (Nor et al., 2019).

\subsection{Building Construction Phase}

During the construction phase, a large amount of different building materials and resources are expanded to have a building constructed or retrofitted (Pui \& Othman, 2019). Energy consumption to lighting, and using the construction machineries, as well as transportation of materials to the construction site, and landfilling the waste materials after or during the construction, are the main causes of CO2 emissions in this phase (Doan et al., 2017).

\subsection{Building Operation Phase}

Generally, residential buildings consume a considerable amount of energy during their lifecycle. In this phase, the electricity and water consumption by residents are the main sources of energy consumption and air conditioning is the main factor of electricity consumption and CO2 emission (Hakkinen et al., 2015).

\subsection{Building End-of-Life Phase}

By the end of shelf life of the building, which in this study is 50 years, we can call the building "out of use". This is the time to demolish the building mechanically or manually [4]. In this stage, the generated waste materials are divided for either recycling and reuse, or to be transferred to landfill. In this phase, energy consumption during landfilling is considered as the main source for $\mathrm{CO} 2$ emissions (Atmaca \& Atmaca, 2015).

\section{CASE STUDIES}

The data analysis of this study was undertaken according to data on details of quantitative characteristics and utility bills of two concrete residential buildings, where the first is a 5-story reinforced concrete structure (Fig. 1) that can be considered as a medium rise structure, while the second is a masonry-concrete semidetached house (Fig. 2), as a smaller sample. The main construction materials in both cases were cement, steel, gravel, sand and water. 


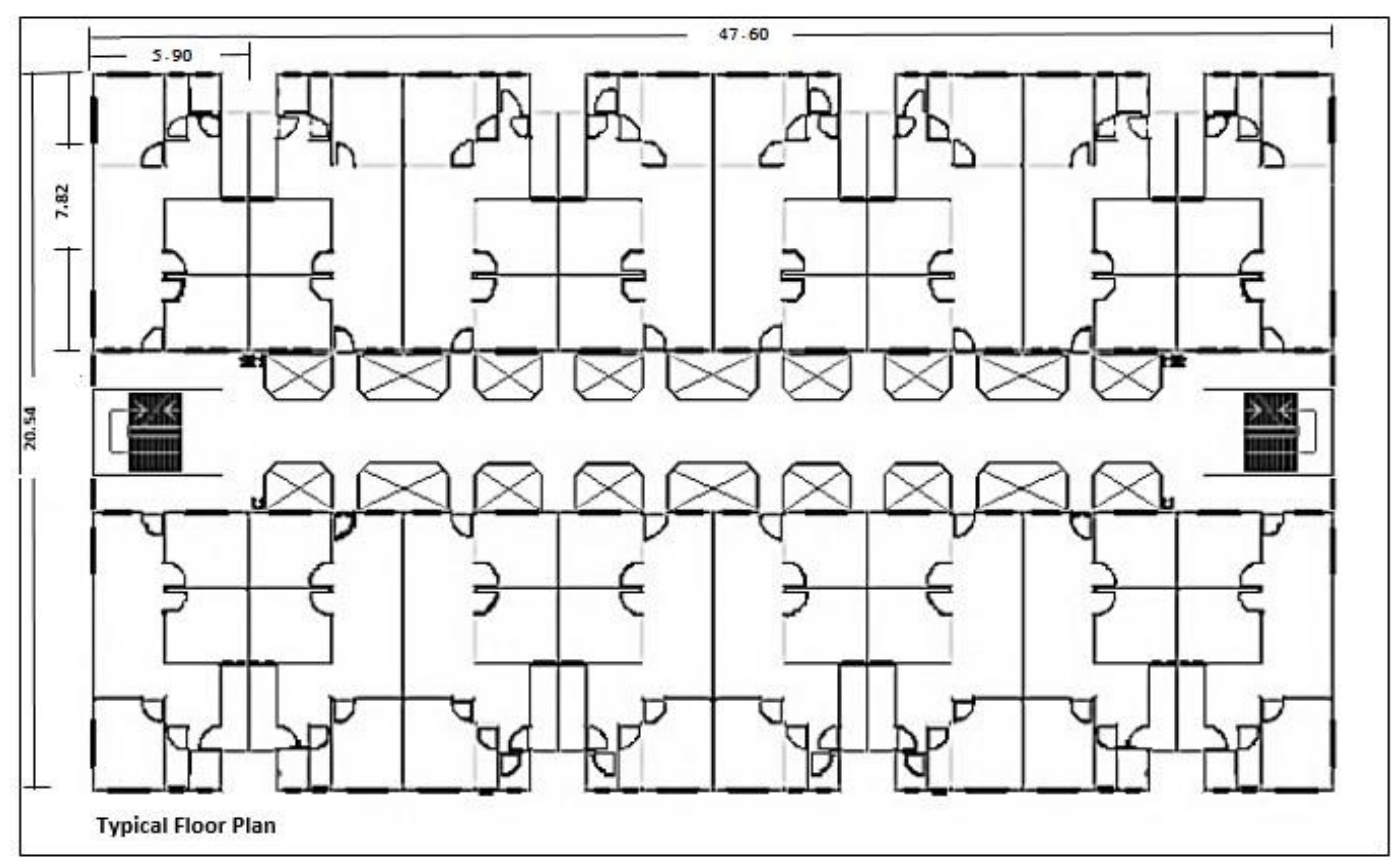

Fig. 1: Layout of reinforced concrete apartment building.

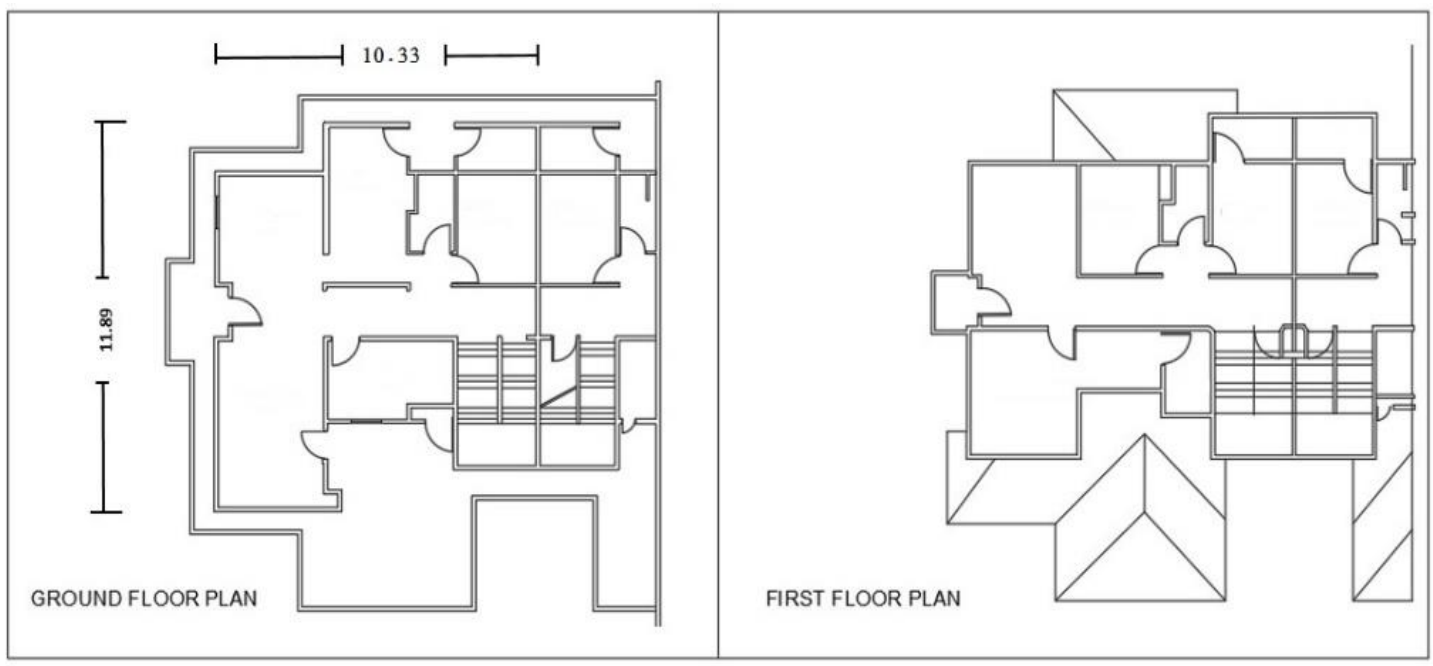

Fig. 2: Layout of masonry-concrete semi-detached house.

\section{RESULTS AND DISCUSSION}

The findings of the study indicated that concrete residential buildings' life-cycle $\mathrm{CO} 2$ emission of the medium rise reinforced concrete structure is 298.91 tons per $100 \mathrm{~m}^{2}$, while for the masonryconcrete building was 318.67 tons per $100 \mathrm{~m}^{2}$. During the life-cycle of a concrete residential building in Malaysia, it is evident that the building's operation phase contributed to almost $85 \%$ of $\mathrm{CO} 2$ emission, which is the highest impact on environment and ecosystem during the building's life-cycle. Second to that is the production phase, which contributed $8-10 \%$ of the $\mathrm{CO} 2$ emission. Construction and end of life of the life-cycle of a concrete structure contributed the least influence in climate change and environmental issues (Fig. 3).

Based on the findings from this study, as well as those reported in literature, it is evident that the best approach to reduce the carbon footprint in residential buildings is to reduce the energy consumption during the building operation phase.

Analysis results of the sources of $\mathrm{CO} 2$ emission in the present case studies indicated that, almost $80 \%$ of $\mathrm{CO} 2$ emission was rooted in the energy consumption, while the industrial and chemical 
process with $15 \%$ was in second place, where it is contributed by cement and steel production. As shown in Fig. 4, other sectors have negligible contribution in $\mathrm{CO} 2$ emission and environmental issues.

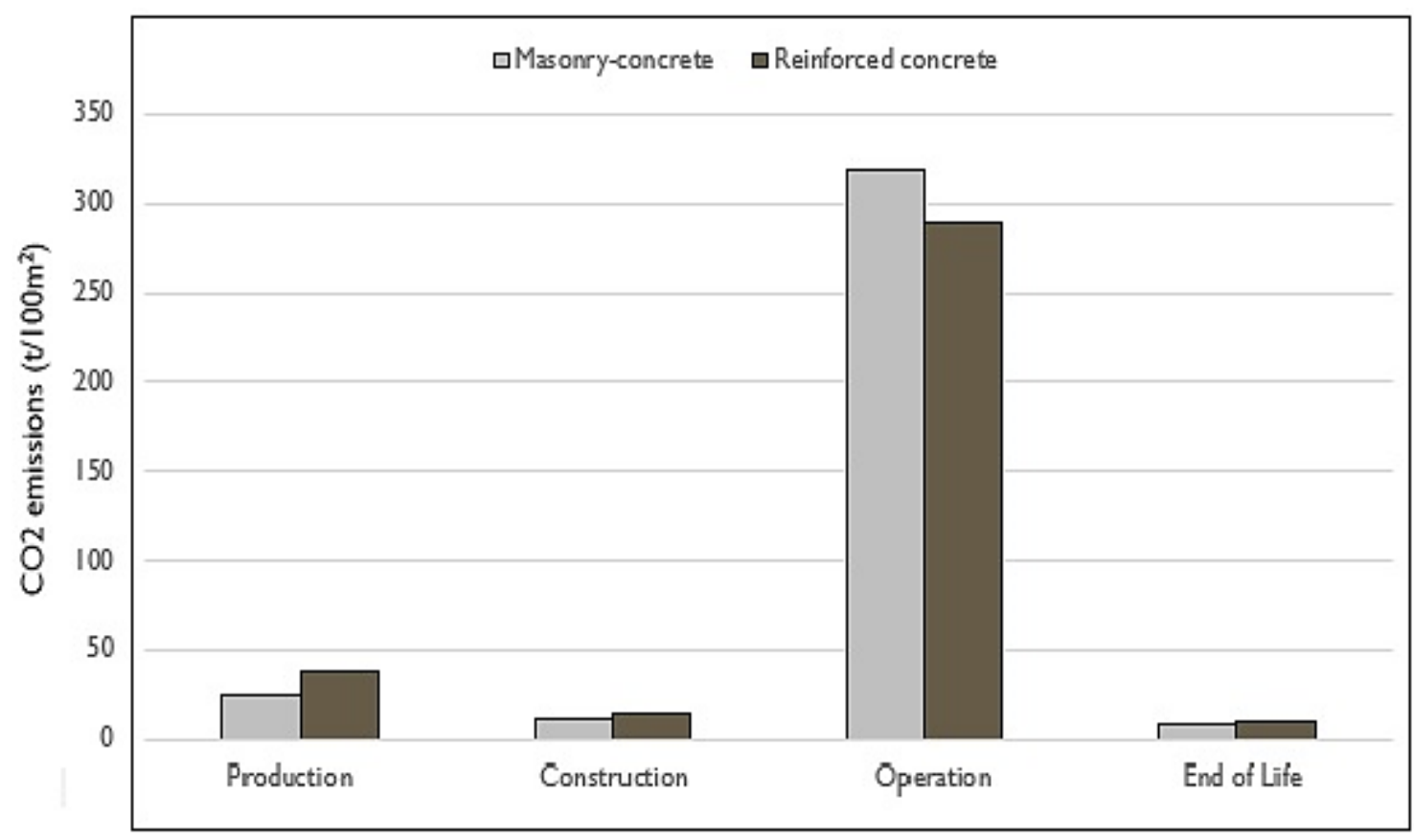

Fig 3: CO2 emission of different life-cycle stages of residential buildings

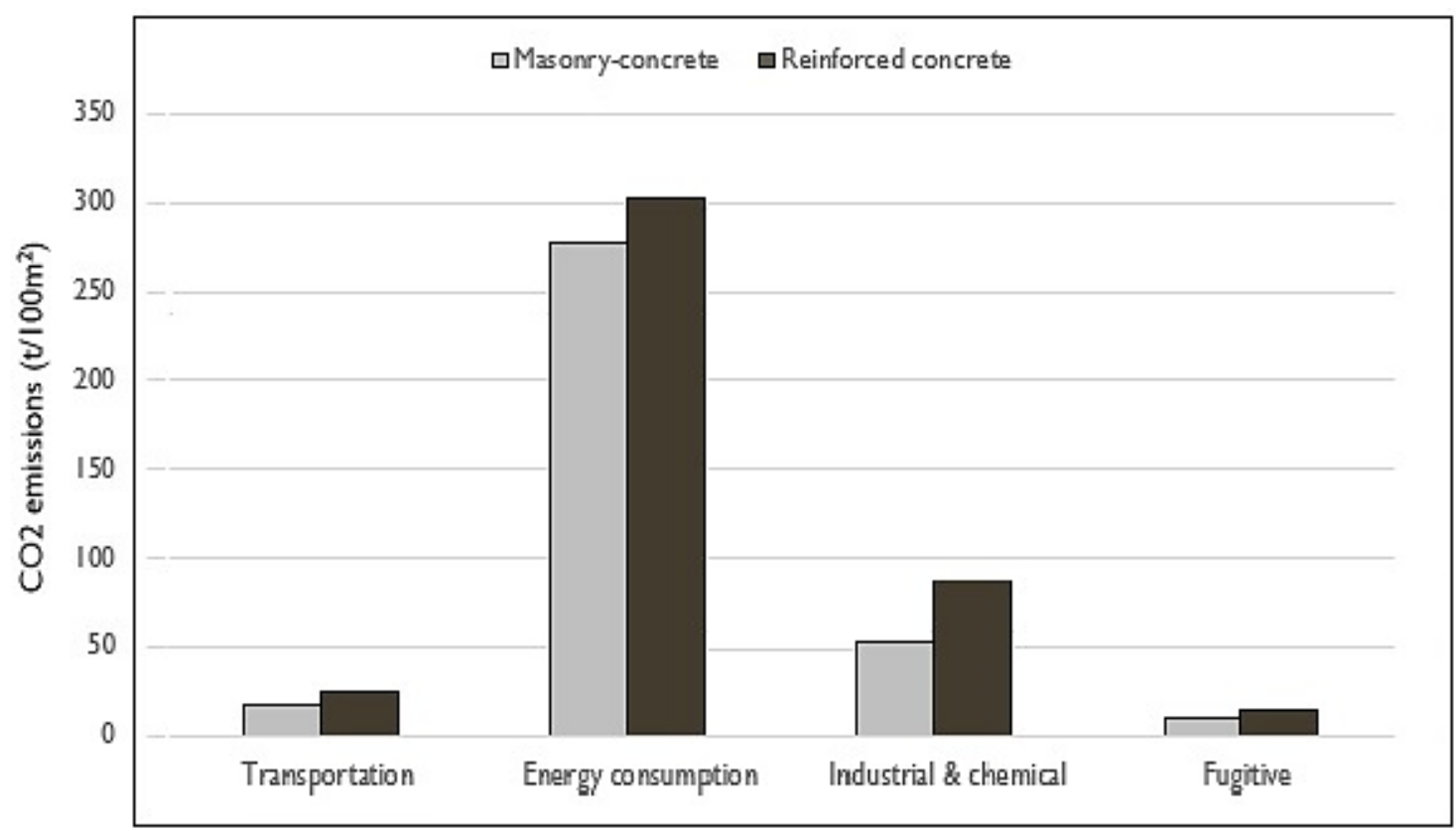

Fig 4: Source of $\mathrm{CO} 2$ emission in residential buildings

The results reported in Fig. 5 indicate that while $\mathrm{CO} 2$ emission of reinforced concrete residential building is almost four times higher than a masonry-concrete structure, but cement with $85 \%$ is the main source of $\mathrm{CO} 2$ emission.
Therefore, it is essential to cut down on the usage of cement in the production of concrete and replace it with other supplementary cementitious materials. 


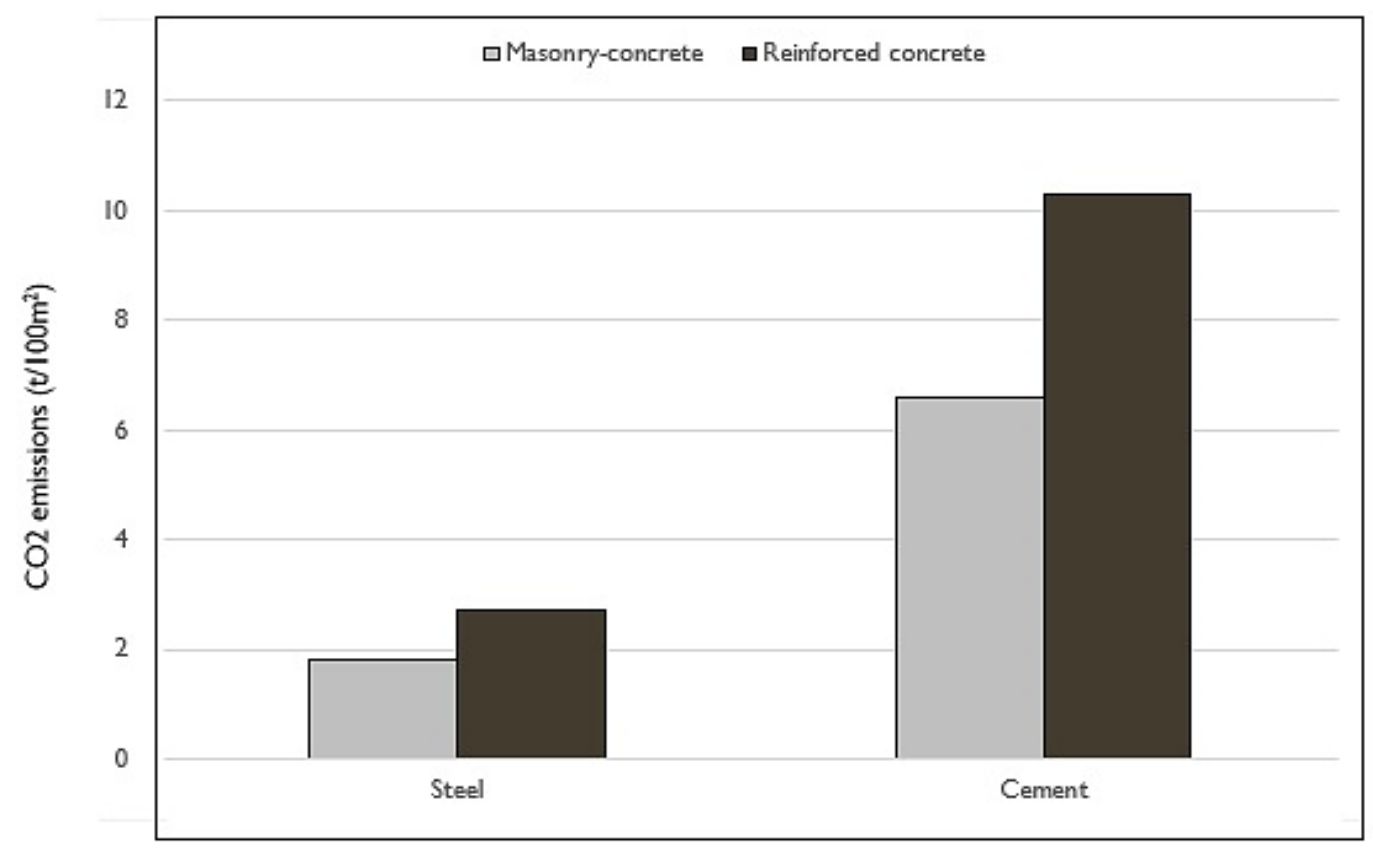

\section{CONCLUSION}

Fig 5: $\mathrm{CO} 2$ emission of different material

In general, concrete structures contribute substantial environmental impact and is one of the biggest sources of $\mathrm{CO} 2$ emission in cities. To analyse $\mathrm{CO} 2$ emissions of concrete structures based on the LCSA framework, we have used the LCCEA model in different phases of two concrete residential buildings' life-cycle in Malaysia. The findings have shown that the main source of $\mathrm{CO} 2$ emission of residential buildings is related to energy consumption during the operation phase, and in some cases, the land footprint. It can be concluded that optimised design and the use of natural ventilation in residential structures, as well as the use of renewable energy for electricity generation can contribute significantly in reducing $\mathrm{CO} 2$ emission and environmental impacts. Further, it is also essential to reduce on the usage of cement in the production of concrete in order to contribute positively towards reduction of $\mathrm{CO} 2$ emission and environmental impact.

\section{ACKNOWLEDGMENT}

The authors would like to express their gratitude to the Ministry of Higher Education, Malaysia and Universiti Kebangsaan Malaysia for providing the necessary funding for this research through the FRGS Grant (FRGS/1/2019/TK01/UKM/02/2).

\section{REFERENCES}

1. Atmaca, A., Atmaca, N. (2015). Life cycle energy (LCEA) and carbon dioxide emissions (LCCO2A) assessment of two residential buildings in Gaziantep Turkey.Energy Build, 102: 417-431.

2 Besten, V., Berawi, M.A., Latief, Y., Crevits, I. (2018). Building incentive structure in the context of green building implementation: From the local government perspective. Journal of Design and Built Environment, 18(2):37-45.

3 Caruso, M. C., Menna, M., Asprone, D., Prota, A., Manfredi, G. (2017). Methodology for Life-Cycle Sustainability Assessment of Building Structures. ACI Structural Journal, 114(2):322-335.

4 Chau, C.K., Leung, T. M., Ng, W. Y. (2015). A review on life cycle assessment, life cycle energy assessment and life cycle carbon emissions assessments on buildings. Appl. Energy, 143:395-413.

5 Dakwale, V.A., Ralegaonkar, R. V., Mandavgane, S. (2011). Improving environmental performance of building through increased energy efficiency: a review. Sustainable Cities and Society, 1(4):211-218

6 Doan, D. T., Ghaffarianhoseini, A., Naismith, N., Zhang, T., Tookey, J. (2017). A critical comparison of green building rating systems. Build Environ, 123:243-260. 
7 Fantili, A. P., Mancinelli, O., Chiaia, B. (2019). The carbon footprint of normal and high-strength concrete used in lowrise and high-rise buildings. Case Studies in Construction Materials, 11: e00296.

8 Fiala, C., Novotna, M., Hajek, P. (2013). Methodology of Life-Cycle Assessment of RC Structures Using High Performance Concrete. Central Europe towards Sustainable Building, Decision-Support Tools and Assessment Method. Prague, Czech Republic.

9 Giesekam, J., Barrett, J. R., Taylor, P. (2015). Construction sector views on low carbon building materials. Build. Res. Inf., 3218:1-23.

10 Hafizzudin, M., Woon, C. O., Raman, S. N., Mohamed, M. F., Nopiah, Z. M. (2019). A Study on the Perception of Architects on The Implementation of Green Roofs in Malaysia: Benefits, Obstacles and Recommendations. Jurnal Kejuruteraan, 31(2):375-381.

11 Hakkinen, T., Kuittinen, M., Ruuska, A., Jung, N. (2015). Reducing embodied carbon during the design process of buildings. J. Build. Eng, 4:113.

12 IPCC. (2018). Guidelines for National Greenhouse Gas Inventories. Prepared by the National Greenhouse Gas Inventories Programme.

13 ISO 14040. (2006). Environmental management - Life cycle assessment Principles and framework. International Organization for Standardization, Geneva, Switzerland.

14. ISO 14044. (2006). International standard. In: Environmental management-life cycle assessmentrequirements and guidelines. International Organization for Standardization. Geneva.

15. Jahandideh, F., Raman, S. N., Jamil, M. (2017). Life cycle sustainability assessment of concrete structures in the Tropics. International Conference on Sustainable Cities, Communities and
Partnerships for Sustainable Development Goals, Kuala Lumpur, Malaysia.

16. Kajaste, R., Hurme, M. (2016). Cement industry greenhouse gas emissions management options and abatement cost. J. Clean. Prod, 112:4041-4052.

17. Kofoworola, O., Gheewala, S. H. (2008). Environmental life cycle assessment of a commercial office building in Thailand. Int. J. Life Cycle Assess, 13:498-511.

18. Latawiec, R., Woyciechowski, P., Kowalski, K. (2018). Sustainable Concrete Performance CO2-Emission. Environments Journal, 5(27):1-14.

19. Miller, S.A., John, V. M., Pacca, S. A., Horvath, A. (2018). Carbon dioxide reduction potential in the global cement industry by 2050. Cement Concrete Researches, 114:115-124.

20. Nor, J. M., Salman, A.M., Che-Ani, A. I., Layoff, R. A., Washi, W. (2019). Identifying the critical components to extend concrete flat roof service life in equatorial climates: a review. Int. Journal of Recent Technology and Engineering. 7:281-284.

21. Pradipto, E., Afif, N. (2019). Increasing eco-performance of concrete blocks through computational design form optimization. Journal of Design and Built Environment, 19(3):1-12.

22. Pui, K. L., Othman, J. (2019). The influence of economic, technical, and social aspects on energy associated $\mathrm{CO} 2$ emissions in Malaysia: An extended Kaya identity approach. Energy 181: 468-493.

23. Ramesh, T., Prakash, R., Shukla, K. K. (2012). Life cycle approach in evaluating energy performance of residential buildings in Indian context. Energy Build, 54:259-265.

24. Rohden, A. B., Garcez, M. R. (2018). Increasing the sustainability potential of a reinforced concrete building through design strategies: Case study. Case Studies in Construction Materials, 9: e00174. 
25. Sharma Varun, A., Shree, V., Nautiyal, H. (2012). Life cycle environmental assessment of an educational building in Northern India: A case study. Sustainable Cities and Society, 4: 2228.

26. Sharif, S., Kamaruzzaman, S.N., Pitt, M. (2017). Implementation framework of green building for government building: Menara Kerja Raya, Malaysia. Journal of Design and Built Environment. 17(2):27-36

27. Sulaiman, M. K., Jamil, M., Fauzi, M. (2018). Percentage Coverage of Tropical Climbing Plants of Green Facade. 2nd International Conference on Architecture and Civil Engineering (ICACE 2018) IOP Publishing, Kuala Lumpur, Malaysia, 401-406.
28. Venkatarama Reddy, B. V. (2009). Sustainable materials for low carbon buildings. Int. J. Low-Carbon Technol, 4(3):175-181.

29. Woon, C.O., Raman, S.N., Shafiudin, M.D., Jamil, M., Fauzi, M. (2019). Development of an assessment method to evaluate the quality of remedial treatments on concrete flat roofs of multiple buildings. Buildings 9, (124):1-15.

30. You, F., Hu, D., Zhang, H., Guo, Z., Zhao, Y., Wang, B., Yuan, Y. (2011). Carbon emissions in the life cycle of urban building system in China - A case study. Ecological Complexity, 8(2):201-212. 